\title{
Do We Always Speak of What We Mean? (Non)Referring Expressions in Discourse
}

\author{
Efthymia Tsaroucha \\ Aristotle University of Thessaloniki \\ eftsar@enl.auth.gr
}

\section{Abstract}

This paper investigates the use of (non)referring expressions by assuming that speakers do not always use reference to speak of what they mean or of what they actually intend to mean. (Non)reference is shaped both by the intention of the speaker and the way the audience makes the identification with what is being referred. Examples are drawn from newspaper articles, headlines, political speeches and advertisements. (Non)referring expressions will not be solely restricted to attributive or equatative functions since their meaning is shaped by the interrelation of the situation derived from a particular context, on the basis of who, to whom, why, when, where and how norms of interaction, interpretation and genres are used.

\section{Introduction}

This paper aims to investigate persuasive language in political and media discourse, particularly advertising language. Persuasion as a form of communication is ubiquitous not only in formal texts, but also in everyday speech, since its basis lies on the transmission of feelings, moods and attitudes towards audiences. Persuasion, however, is composed of two versions. On the one hand, persuasion can be termed as a kind of "language-like representations that capture the ideational content of the mind" (Eysenck and Keane 2000: 246), or to put it better as an information processing activity, in which thoughts are actively manipulated to create new beliefs and attitudes. On the other hand, persuasion is interrelated with the notions of conviction and manipulation. In particular, Woolbert (1923: 19) claimed that the fixing of a line between what is called conviction and what is called persuasion could not be successfully done because both notions seem to seek the same end. When it comes to

\section{(cc) BY-NC-ND}


the interrelation of persuasion with manipulation Campell ([1989] 2000: 57) proposed that manipulation refers to the degree according to which the language user is a willing or a naïve participant in the process of being compelled towards products, or ideas. In this paper, I have decided to investigate the first version of persuasion, without however, ignoring the fact that language itself can be misleading in many cases since the hidden meaning behind utterances and texts cannot be conceived at a superficial reading; on the contrary, it is my belief that persuasive language should be analyzed on the basis of both linguistic knowledge and of social, political, economical and cultural factors as well.

After having presented the version of persuasion I am going to analyze, I should also note that approaching linguistic meaning under discourse analysis and critical discourse analysis concerns at a starting point the relationship between the discourse and the speakers and hearers, by and for whom it is produced. To be more precise, meaning is explained by means of analyzing the way speakers take and relinquish the role of the speaker, social roles and relationships between the participants (Coulthard 1981: 11). According to Fairclough and Wodak (1997: 258) critical discourse analysis sees discourselanguage use in speech and writing as a form of social practice due to the dialectical relationship between a particular discursive event and the situations, institutions and social structures which frame it.

As it was mentioned in the very beginning of the introduction, persuasive language exists not only in texts but also in every day speech. In this respect, critical linguistics and critical discourse analysis focus not only on texts, spoken or written as objects of inquiry. On the contrary, individuals or groups should account on a theorization and description of both social processes and structures in order to create meanings in their interaction with text (Wodak 2001a: 3). As Jager (2001: 35) points out discourse creates the conditions for the formation of subjects and the structuring and shaping of societies.

With regard to the aforementioned remarks, I would like to add that the notion of persuasion is strongly related to the concept of power. Power is not simply dependent on grammatical forms of a text, especially, if we consider speaker's control over a social affair regarding the genre of a text; on the contrary power is reflected in the way people make use of grammatical structures and with regard to this, it shapes meaning and creates ideology. Power, in my opinion, constitutes a fundamental component of discourse and critical discourse analysis since it encompasses a wide range of discourses, such as news, political speeches and advertisements. In this paper, I will attempt to analyze the concept of power and its relation with persuasion on the grounds of referring expressions (either if they serve as counterparts of reference, i.e., deictics, proper names, generics, indexicals etc., or as non-referring expressions).

In addition, I view that a critical approach to persuasive language indicates that the concept of power can be interpreted on the basis of certain features. To 
be more precise, desirability, importance-significance, warrantability, probability, comprehensibility, obviousness, utility, expectability and appropriateness contribute to the interpretation of persuasive language simply because they are subject to certain notions like respect, freedom, efficiency, morality, trust (worthiness), legality, virtuousness, beauty, wealth, quantity, magnitude, scope and dimensionality, which by definition aim at communicating ideas or products (Graham 2003: 114).

Summarizing the introductory part of the paper, I should note that the investigation of persuasive language on the grounds of (non)referring expressions and under the discipline of discourse and critical discourse analysis indicates that the combination of both linguistic and extra-linguistic knowledge is necessary. In the following sections I will attempt to propose that the usage of (non)referring expressions in political speech and in advertising serves as persuasive tools because the function of (non)reference is strongly related with the concept of power. As it will be shown, (non)referring expressions, when used in particular discourses, such as politics reflect a certain kind of ideology and point of view, which affects the cognition of the given audience.

In conclusion, I should note the aim of this paper is to emphasize the "hidden" meaning of the overall of context, in which (non)referring expressions serve as an instance of persuasive language. My claim is based on Scollon's (2003: 169) argument stating that language (in our case, the use (non)referring expressions) affects the cognition of its speakers, but at the same time they should be aware of the circumstances in which they come to use the language in question. Lastly, a strong emphasis will be given on context, since as it has been proposed contextual analysis is a combination of not only immediate language or internal co-text, but also of extra-linguistic sociological variables reflected in the broader sociopolitical and historical contexts (Wodak 2001b: 67).

\section{The Special Status of News, Political Speeches and Advertisements as Discourse}

This section aims to investigate the discursive dimensions of news, politics and advertisements. In particular, it will be argued that these discourses have a strong and dynamic impact on the presupposition of knowledge as they affect judgment and appreciation. Judgment and appreciation should constitute a fundamental component of critical discourse analysis, as they point at deepseated processes of marketization (Billig 2003: 36) and institutional positions (Chouliaraki and Fairclough 1999: 9), which shape the special status of news, politics and advertisements. 
To begin with the special status of news as discourse, it should be noted that their status lies on cultural determination, report of the event, register in terms of generic structure and information addressed either to a general public or to an objective point of view or even to journalist's self image (Caldas-Coulthard 2003: 274-5). Moreover, news selection is regulated by general news values such as frequency, size of the event, (un)ambiguity or clarity of the event, (un) predictability, (un)expectedness, mixture of different kinds of events, reference to elite persons and nations, personalization and negativity (ibid: 277).

According to Meyer (2001: 27) there are certain discursive strategies the researcher should follow, while analyzing news; for instance, nomination, predication, argumentation, perspectivation and intensification are necessary steps for the analysis of the particular genre. In my understanding the application of this mechanism is grounded by some further steps the researcher should follow. I think that focus on semantic macrostructures, an extensive analysis of local meanings and formal structures (by taking into account specific linguistic realizations) and context result in a complete and critical processing of news.

Moreover, politics as a discourse type concerns the overall institutionalization of public sphere. According to Calhoum (1992: 12-13) politics is characterized by a kind of social intercourse (status), mutual willingness to accept given roles, notion of common interest, or right policy and problematization of areas that until now may not have been questioned. Public space is generated by public discourse due to the link between power, legitimacy and discourse. Benhabib (1992: 85-95) proposed a discursive model of public space according to which the issue of social differentiation is reflected in the aspects of modernity, personality formation and bifurcation, and public space should keep a reflexive and critical attitude towards the individuals.

At this part, I would like to propose that the concept of public sphere could be studied as a feature of public discourse, or even as an instance of political discourse. More precisely, if we consider that the language of politics is composed of a body of private persons, which has to discuss social matters in public, we could further consider that the issues of discursive interaction and public opinion need to be dominant.

Lastly, advertisements as a discourse type are composed of text, which in its formal definition is used to mean linguistic forms, related with context. According to Cook (1992: 1-2) the context of advertisements includes substance (physical material which carries text, music and pictures), paralanguage (meaningful behavior accompanying language such as voice quality, facial expressions and choice of type face), situation (properties and relations of objects and people in the vicinity of the text, as perceived by the participants), co-text (text that precedes or follows that under analysis), inter-text (text which the participants perceive as belonging to other discourse), participants (senders, addressers, 
addressees and receivers) and function (what text is intended to do by the senders and addressers, or perceived to do by the addressees).

It is further worth mentioning that the substance of advertisements lies on communication. According to Cook (1992: 23-25) advertisements use secondary substances of language and should be analyzed by virtue of their purposes such as, attention-getting, talking micro-chips, novel substance or fixing the product more firmly in the memory by actively involving the reader. Despite the usage of secondary substances of language, advertisements are also rich in signs, which in their turn aim to serve as persuasive tools. According to Danesi (2002: 17) signs mediate reality and never really denote or represent the whole truth, because they "constitute convenient selections from the infinite realm of the knowable".

In the following section, it will be claimed that the "hidden" meaning of both news along with politics and advertisements is governed not only by the written text, but also by the current signs. As it will be shown, (non)referring expressions in relation to signs construct associations and shape meaning. Signs along with (non)referring expressions constitute a fundamental part of visual modality, which in the case of political speeches, news and advertisements contributes to the perception of a hidden quality and latency of the text. Lastly, the methodological analysis I have decided to follow is based on Blanchard's (1980: 22) observations on the semiological reading of texts. According to Blanchard (1980: 22) a semiological reading of a text generally entails the perception and the internalization of a stylistic structure, which consists of a self-referential value of the text. Thus, the description of any discourse type holds our attention because something is partial and something else may, or has to be missing.

\section{On (Non) Referring Expressions}

The theorization of referring expressions primarily deals with the notions of deixis, definiteness, (in)direct reference and indexicality. Among the years of theoretical descriptions on meaning various rules, exceptions, regulations and even newer counterparts of referring expressions emerged. For reasons of economy I will not discuss all these theoretical accounts; however, I will present a definition on the counterparts of reference by investigating their function within genres of persuasive language, which constructs the subject of this paper. I will attempt to connect each category of referring expressions with the "hidden" meaning lying behind political speeches, advertisements and newspaper headlines.

Firstly, deixis and deictic expressions constitute a fundamental part of referentiality. According to Huang (2007: 132), the term deixis derives from the Greek verb /dihno/, which means to show or to point out, and it is interrelated both with the linguistic structure and the context in which language is used. 
The process of pointing or showing encodes universal features, no matter how strong cultural and linguistic differences may be, since a language without deictics cannot serve communication. Lastly, the organization of deixis follows an egocentric way because it represents not only the speaker of an utterance ("deictic origo"), but also the audience ("ground zero") (Huang 2007: 135).

Furthermore, deictic expressions are subcategorized into person, spatial and temporal aspects. To be more precise, person-social deixis concerns addressoraddressee relations and possibly addressor-general (public) audience relations. Social-person deixis is ruled by "[...] the codification of the social status of the speaker, the addressee, or a third person or entity referred to, as well as the social relationships holding between them" (Huang 2007:163). The sub-category of spatial deixis concerns the place of the utterance and is introduced with locative adverbs, demonstratives, and determiners; it is also possible to show a similar sort of dominance relation to the personal pronouns (Cruse 2004: 333). Finally, temporal deixis refers to the so-called "time axis", which stands for the moment the utterance is produced and at the same time it is grounded as the reference point.

After having described the behavior of deictic expressions, I would like to point out that deixis is widely used in advertisements since its combination with visual modality draws our attention effortlessly towards the current product. The given advertisement is composed of a text, weaved together with the logo of the national bank of Greece (the trading product), in order to promote its creditworthiness over other banking loan agreements.

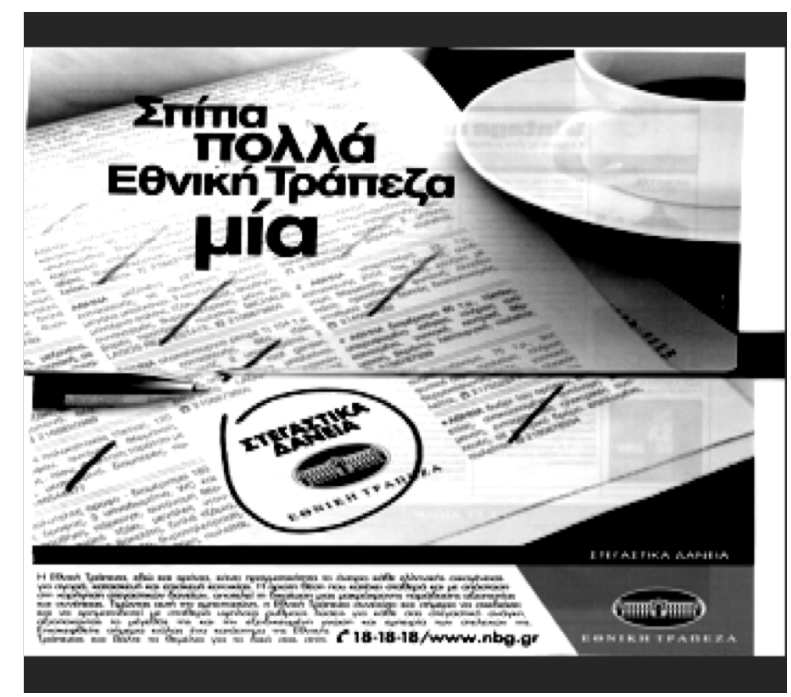

Figure 1. Advertisement 
As I have mentioned in the previous section (where I have argued for the special status of adverisements as a discourse type), one of the basic purposes of the particular genre is to present the product more firmly by actively involving the reader. In the particular example, the reader seems to seek for the most convenient financial transaction, if we consider the fact that other possible mortgage packages are crossed out (figure 1).

It seems to me that in the given advertisement, we face a complex instance of deixis since the indefinite description [mia] ("one") functions deictically (by embracing both spatio-temporal and social readings), because it refers to the national bank of Greece, which happens to be pointed out (the trading product, as illustrated in Figure 1, is circled). The national bank of Greece is launched as the right place for such a transaction and at the same time the advertisement urges its readers to choose the trading product by constructing the implication that their consumer dilemma came to an end. My assumption derives from the fact that opponent products being crossed out, whereas the bank's logo is circled. Lastly, with regard to the social function I believe that the deictic expression [mia] ("one") is associated with the socio-economic situation of Greece, whereby the overall credit system is under devaluation; thus, the particular bank may ensure stability and credibility.

Along the same lines, it is also worth mentioning that deixis and reference are interrelated, and reference is further expanded into three subcategories: definite, indefinite and generic. Firstly, definite reference is defined as the identification of referents (of definite descriptions), which helps the hearer to reconstruct what the speaker has expressed (Cruse 2004:320). Definiteness is known as the familiarity hypothesis since the denoted entities are familiar to both speakers and hearers so that general knowledge in relation to crossreference or associative uses can arise (Lyons 1999: 4). Secondly, identifiability in combination with the notions of inclusiveness and uniqueness is in parallel relations with definiteness because the hearer is in a position to exploit clues in the linguistic and extra-linguistic context so that to establish the identity of the referent (Lyons 1995: 5-6). Lastly, generic reference concerns the general or overall reference towards a class of referents whereby something can be predicated of the whole class referred to, or of each member of the class (Cruse 2004: 320, 323).

Is it actually possible for a referring expression not to be purely referential if it brings together all the above functions? I think that in persuasive language and particularly in media discourse the perception and the internalization of a stylistic structure is generated from a hidden quality or latency; something may be partial or something else has to be missing.

(1) Chronology of Terror, 11 September 2001

(USA Today) 
This example comes from a newspaper headline and equates a particular social situation with a specific date. In my understanding this headline can be treated as an elliptical equatative clause (comma links the two expressions and equates them). Ellipsis is expected in newspapers' headlines either for reasons of economy or for stylistic factors regarding news selection such as personalization, negativity and (un)predictability (as analyzed in Section 2).

As a consequence, the equation of the expression "chronology of terror" with "11 September 2001" refers to a definite and inclusive event, which is familiar to the readers because they are able to extract clues (either from the linguistic or extra-linguistic context) and identify the referent. Despite the fact that the event is definite and specific (a particular temporal and spatial location), the public sphere in which it refers to is not. It concerns a body of participants, either passive (the relatives of the victims of the terrorist attack, the overall body of US citizens, and citizens of foreign countries as well) or active (the victims of the terrorist attack). In this respect, I claim that the persuasive function of the given headline, despite the ellipsis, aims to introduce the terrorist attack of 9/11, as a chronology of terror, which every man who is opposed to violence has to refute. In the particular case, it is observed that a definite referent may also function as the associative referent of a mass public group. As a consequence, definite reference can co-exist with generic reference if we think of media discourse as a more flexible genre (news) by virtue of structure and style (ellipsis).

What is more, I view that the distinction between constant-variable reference on the one hand and objectual-descriptive from the other is needful for the analysis of (non)referring expressions in the field of persuasive language. According to Saeed (1997: 26-27) constant reference concerns expressions that have the same referent across a range of different variables whereas variable reference denotes expressions, which are totally dependent on each context (1997:26-7). Extension is a part of variable reference because referents can be either picked out by uttering the expression in a particular context or extracted from a set of things, which could possibly be the referent of that expression (1997:27). Lastly, as far as the distinction between objective and descriptive reference is concerned, Bach (1987: 66) supports that the first type occurs when the addressee identifies the referent despite of what the addressor has already produced, while the second type emerges in case that the speaker intends to talk about whatever uniquely satisfies the individual concept (and the hearer is able to recognize the determining referent).

The examples below are drawn from newspaper articles and concern political statements. In (2) the "US president" functions as constant reference because it expresses the same referent across the world. However, the expression "an apparent terrorist attack" is used attributively not only because of the presence of the propositional attitude verb "call", which denotes personal perspective 
and intention, but also because hearers are in a position to make the exact identification with what the speaker intends to denote by relying either on the particular context, or on general and shared knowledge about the world. In (3) the expression "a White House spokesman" is used indefinitely, while the expression "a threat" is an instance of definite reference, because it illustrates a particular political situation. If we assume that the utterance concerns a political statement (since the speaker a White House's spokesman), we could also claim that the audience expects him/her to refer to the current political agenda, as the special status of politics foresees (Section 2) and they can further perceive spokesman's words as the intended referent.

(2) US president [...] called the destruction in New York "an apparent terrorist attack on our country" and ordered a full-scale investigation to hunt down the folks who committed this act. (The New York Times)

(3) Yesterday a White House spokesman stressed Iraq was a threat under Saddam before the 2003 invasion.

(The Daily Mirror)

\section{A Step beyond Reference: Indexicality, Politics and the Public Sphere}

As far as indexicality is concerned, Koutoupi-Kitis (2009-10: 262) claims that there are certain elements of speech, geographically or socially located, which are considered to be indexes that not only put the speaker in a particular situation, but also witness details concerning speaker's identity. Under this proposal, indexicality is another type of reference, which carries, apart from purely contextual or structural information, some further details deriving from the general world context, speakers' inferences and idiosyncratic beliefs.

This type of reference surpasses the strict linguistic environment of the utterance and it is associated with semantic features. More specifically, Cappelen and Lepore (2002: 276) claim that the nature of indexicals is constrained both by their syntactic and epistemological side; the former refers to anaphoric relations, whereas the latter generates certain kinds of a priori truths.

From my point of view, if the linguistic meaning of an expression is self-referential with its structure, it grounds universal truths; thus, any referring expression of this type must have a universal character, which undergoes denotational changes at any given context. I also believe that in the case of persuasive language, both the syntactic and epistemological side of indexicals is in a cline. To be more precise, indexicals that participate in overt anaphoric relations, like the personal pronoun "I", are deep in the sense that they make precise what is universally true. 
The observation of the character of the indexical ("I") at any given context, witnesses its function as the agent of that context.

In (4) the indexical "I" refers to the speaker of the particular utterance, the agent of the particular context; The political statement is drawn from Obama's campaign speech at the Democratic National Committee (fall meeting 2007), where he was called to support his predominance over his political opponent for the presidential elections.

(4) The only reason I am standing here today is because somebody somewhere stood up when it was risked.

(DNC)

However, I view that its indexical function is expanded into descriptive reference because the speaker intends to talk about whatever "[...] uniquely satisfies the individual concept that the hearer is able to recognize as determining the referent" (Bach 1987:66). I suppose that the personal pronoun "I" designates multiple identities because the speaker is presented both as a political figure and as the expectant president and even as the most right choice for the elections, because the referring expression is extended to general addressees like "somewhere" and "somebody".

Consequently, I propose that in politics, when the personal pronoun "I" functions as an indexical is neither a pure indexical nor a pure referring expression. I think that it should be approached as an in-between reference and indexicality element. It functions as a collective a body since it expresses a set of referents. It embraces the political ideology of the speaker by invoking audience's political acceptance.

\section{Concluding Remarks}

This paper investigated the function of (non)referring expressions under the field of media and political discourse. Instances of these discourses (such as advertisements, political speeches, newspaper articles and headlines) showed a strong flexibility by virtue of structure and style. In these genres language can be used in a more expressive manner on the basis of speaker's intentions and beliefs. The factor of public sphere with reference to social, political and economical features shapes the way language is used.

The initial question of the paper, if we always speak of what we mean or if we always mean of what we speak, was answered multiply. Firstly, deictic expressions can encompass spatial, temporal and social readings simultaneously. Secondly, definite reference equates different expressions, if hearers are in a position to make the exact identification with what the speaker intends to denote. Moreover, referring expressions cannot be approached as purely referential, if their 
readings are a combination of a range of different variables, either extended or extracted from a set of things, which hearers may be in a position to recognize as the determined referent(s).

In conclusion, I believe that reference without reference is ubiquitous in language, in spite of genres and discourses. However, cases of "misleading" language can be more easily examined in more formal discursive structures because of effortless access (either with respect to advertisements or news). The theorization of rules and regulations of (non)referring expressions is shaped by addressor-addressee, addressor-audience and addressee-public sphere relations. As it was shown in this paper, the use of (non)referring expressions in certain discourses, such as news, political speeches and advertisements has a persuasive function since it reflects a certain kind of ideology and social behavior appealing to the target audience. 


\section{References}

Bach, K. 1987. Thought and Reference. Oxford: Oxford UP.

Benhabib, S. 1992. Models of Public Sphere: Hannah Arendt, the Liberal Tradition and Jürgen Habermas. In C. Calhoun (ed.), Habermas and the Public Sphere. Cambridge, Massachusetts: MIT Press, 73-98.

Billig, M. 2003. Critical Discourse Analysis and the Rhetoric of Critique. In R. Wodak and G. Weiss (eds.), Critical Discourse Analysis: Theory and Interdisciplinarity. New York: Palgrave Macmillan, 35-46.

Blanchard, M.E. 1980. Description: Sign, Self, Desire: Critical Theory in the Wake of Semiotics. The Hague and New York: Mouton Publishers.

Caldas-Coulthard, C.R. 2003. Cross-Cultural Representation of 'Otherness' in Media Discourse. In R. Wodak and G. Weiss (eds.), Critical Discourse Analysis: Theory and Interdisciplinarity. New York: Palgrave Macmillan, 272-296.

Campell, C. [1989] 2000. The Puzzle of Modern Consumerism. In M. Lee (ed.), The Consumer Society Reader. Malden, Massachusetts: Blackwell, 48-72.

Capellen, H. and Lepore, E. 2002. Indexicality, Binding Anaphora and a Priori Truth. Analysis, 62 (4): 271-281.

Chouliaraki, L. and Fairclough, N. 1999. Discourse in Late Modernity: Rethinking Critical Discourse Analysis. Edinburgh: Edinburg UP.

Cook, G. 1992. The Discourse of Advertising. London and New York: Routledge.

Coulthard, M. 1981. An Introduction to Discourse Analysis. London and New York: Longman. 
Cruse, A. 2004. Meaning in Language. Oxford: Oxford UP.

Danesi, M. 2002. Understanding Media Semiotics. London, UK and New York: Arnold, Hodder Headline Group and Oxford UP.

Eysenck, M. and Keane, M. 2000. Cognitive Psychology, $4^{\text {th }}$ edition. Hove: Psychology Press Ltd.

Fairclough, N. and Wodak, R. 1997. Critical Discourse Analysis. In T. van Dijk (ed.), Discourse Studies: A Multidisciplinary Introduction. London: Sage, 258-284.

Graham, P. 2003. CDA and Evaluative Meaning: Interdisciplinarity as a Critical Turn. In R. Wodak and G. Weiss (eds.), Critical Discourse Analysis: Theory and Interdisciplinarity. New York: Palgrave Macmillan, 110-129.

Huang, Y. 2007. Pragmatics. Oxford: Oxford UP.

Jager, S. 2001. Discourse and Knowledge: Theoretical and Methodological Aspects of A Critical Discourse and Dispositive Analysis. In R. Wodak and M. Meyer (eds.), Methods of Critical Discourse Analysis (1st edition). London: Sage, 32-62.

Kitis-Koutoupi, E. (2009-10), (MS). Semantics: The Fundamentals of Meaning in Language. Thessaloniki: Aristotle University.

Lyons, C. 1999. Definiteness. Cambridge: Cambridge UP.

Lyons, J. 1995. Linguistic Semantics, An Introduction. Cambridge: Cambridge UP.

Meyer, M. 2001. Between Theory, Method and Politics: Positioning of the Approaches to CDA. In R. Wodak and M. Meyer (eds.), Methods of Critical Discourse Analysis (1 ${ }^{\text {st }}$ edition). London: Sage, 14-31.

Saeed, J. I. 1997. Semantics (1 $1^{\text {st }}$ edition). Oxford: Blackwell.

Scollon, S. 2003. Political and Somatic Alignment: Habitus, Ideology and Social Practice. In R. Wodak and G. Weiss (eds.), Critical Discourse Analysis: Theory and Interdisciplinarity. New York: Palgrave Macmillan, 167-198.

Wodak, R. 2001a. What Critical Discourse Analysis Is About- A Summary of Its History, Important Concepts and Its Developments. In R. Wodak and M. Meyer (eds.), Methods of Critical Discourse Analysis (1st edition). London: Sage, 1-13. 
Major Trends in Theoretical and Applied Linguistics

Wodak, R. 2001b. The Discourse-Historical Approach. In R. Wodak and M. Meyer (eds.), Methods of Critical Discourse Analysis (1st edition). London: Sage, 63-94.

Woolbert, C.H. 1923. The place of logic in a system of persuasion. The Quarterly Journal of Speech Education, 9(4): 19-39. 